\title{
Antonella Emina, Léon-Gontran Damas. Les détours vers la Cité Neuve
}

Roberto Ferraroni

\section{(2) OpenEdition}

1 Journals

\section{Edizione digitale}

URL: https://journals.openedition.org/studifrancesi/21789

DOI: 10.4000/studifrancesi.21789

ISSN: 2421-5856

\section{Editore}

Rosenberg \& Sellier

\section{Edizione cartacea}

Data di pubblicazione: 1 décembre 2019

Paginazione: 616

ISSN: 0039-2944

\section{Notizia bibliografica digitale}

Roberto Ferraroni, «Antonella Emina, Léon-Gontran Damas. Les détours vers la Cité Neuve», Studi Francesi [Online], 189 (LXIII | III) | 2019, online dal 01 mars 2020, consultato il 11 novembre 2021. URL: http://journals.openedition.org/studifrancesi/21789; DOI: https://doi.org/10.4000/studifrancesi. 21789

Questo documento è stato generato automaticamente il 11 novembre 2021.

\section{(c) (1)}

Studi Francesi è distribuita con Licenza Creative Commons Attribuzione - Non commerciale - Non opere derivate 4.0 Internazionale. 


\title{
Antonella Emina, Léon-Gontran Damas. Les détours vers la Cité Neuve
}

\author{
Roberto Ferraroni
}

\section{NOTIZIA}

Antonella Emina, Léon-Gontran Damas. Les détours vers la Cité Neuve, Paris, L'Harmattan, 2018, $168 \mathrm{pp}$.

1 Nel saggio proposto da Emina, la studiosa traccia un'approfondita analisi dell'opera di Léon-Gontran Damas, poeta originario della Guyana francese e pioniere della Négritude, movimento nato dall'incontro tra Léopold Sédar Senghor, Aimé Césaire e appunto Damas. Il volume vuole essere un viaggio nella poesia dell'autore sudamericano, attraverso l'analisi della sua, sebben ridotta, produzione letteraria.

Dopo i ringraziamenti iniziali e una breve introduzione, il saggio si divide in due parti. La prima si concentra sull'autore e la sua opera, articolandosi a sua volta in due capitoli: il primo, dedicato alla vita dell'autore, narra gli eventi di maggior rilievo che l'hanno caratterizzata, partendo dall'infanzia di Damas nella Guyana francese, passando per la perdita della madre e poi dell'amata zia, per poi arrivare al suo trasferimento in Francia dove avrà la possibilità di dar libero sfogo alla sua arte; il secondo capitolo è, invece, una descrizione attenta e precisa della sua produzione poetica: Emina descrive infatti scrupolosamente le quattro raccolte pubblicate dall'autore mentre era ancora in vita e l'ultima, postuma, data alle stampe più di trent'anni dopo la sua morte. Questo secondo capitolo è indubbiamente più "tecnico" del precedente, e sembrerebbe rivolto principalmente a un lettorato esperto che ha già avuto modo di confrontarsi con l'opera del poeta.

3 La seconda parte del saggio, invece, è divisa in tre capitoli e rappresenta un'analisi approfondita della poesia di Damas da un punto di vista sia contenutistico che stilistico. I primi due capitoli sono facilmente accessibili per qualsiasi lettore, in quanto affrontano la produzione letteraria del poeta da un punto di vista del contenuto, 
informandolo su quali siano gli assi principali attorno ai quali si sviluppa la sua scrittura: il riconoscimento, ad esempio, dell'esistenza di due civiltà antagoniste, quella francese e quella dell'"Altro", a cui lui appartiene; il dolore, che ha caratterizzato gran parte della sua esistenza; la Guyana, il paese d'origine che vive nei suoi ricordi; l'Io interiore del poeta, raccontato tramite la descrizione delle fasi che ha attraversato nel corso degli anni. Al contrario, l'ultimo capitolo richiama il capitolo conclusivo della sezione precedente e affronta le tecniche e i meccanismi della scrittura poetica di Damas. Illuminante per chi conosce già i testi, potrebbe risultare di difficile accesso per chi non ha mai avuto la possibilità di leggere l'opera dello scrittore francofono. Il volume è completato da una breve conclusione e una sezione bibliografica estremamente ampia e ben fatta.

4 Antonella Emina con questo suo lavoro rivela una profonda conoscenza di Damas e della sua poesia, mettendone in luce gli elementi salienti, gli aspetti che hanno reso il poeta una figura centrale per la nascita del movimento della Négritude, le ragioni per cui la sua opera sia stata, e sia ad oggi, una pietra miliare per la letteratura francofona. Lo fa con uno stile chiaro e pulito, che rimane tale anche nei capitoli più "tecnici", riservati agli addetti ai lavori. 